\title{
Effects of Synchronous Computer-Mediated Communication and Face-to-Face Interaction on Speaking Skill Development of Iranian EFL Learners
}

\author{
Hakimeh Shahrokhi Mehr (Corresponding author) \\ Department of English Language, Ahar branch, Islamic Azad University, Ahar, Iran \\ Tel: 98-914-401-1593 E-mail:shahrokhi.mehr@yahoo.com \\ Masoud Zoghi \\ Department of English Language, Ahar branch, Islamic Azad University, Ahar, Iran \\ Tel: 98-914-412-2624 E-mail: Dr.m.zoghi@gmail.com \\ Nader Assadi \\ Department of English Language, Ahar branch Islamic Azad University, Ahar, Iran \\ Tel: 98-914-116-7312 E-mail: Naderassadi@yahoo.com
}

Received: 05-05-2013

Accepted: 09-06-2013

Published: 01-09-2013

doi:10.7575/aiac.ijalel.v.2n.5p.36

URL: http://dx.doi.org/10.7575/aiac.ijalel.v.2n.5p.36

\begin{abstract}
The traditional form of teaching speaking skill has been via face-to-face (FTF) interaction in the classroom setting. Today in the computer age, the on-line forum can provide a virtual environment for differential communication. The pedagogical system benefits from such technology improvement for teaching foreign languages. This quasiexperimental research aimed at comparing the effects of two instructional strategies: synchronous computer-mediated communication (SCMC) and FTF interaction. For this purpose, 60 EFL learners were selected from a private language institute as the control $(n=30)$ and experimental $(n=30)$ groups. A speaking test, designed by Hughes (2003), was administered as pretest and after a 12 -session treatment the same test was administered as the posttest. The result obtained showed that participants taught based on SCMC fared better than those that were taught according to FTF interaction. Based on the findings of the current study, it is recommended that EFL teachers incorporate computermediated communication into their pedagogical procedures.
\end{abstract}

Keywords: Synchronous Computer-Mediated Communication, Face-to-Face Interaction, Speaking Skill.

\section{Introduction}

The expansion of the Internet and other new technologies has affected education systems and the field of curriculum has accordingly undergone many shifts over the years. The involvement of the technology into the process of teaching and learning may create new ways for instruction. The traditional ways that instructors teach and students learn, continue to be modified by these improvements and Internet has provided the opportunity to study online.

Computer-mediated communication (CMC) is a kind of "communication that takes place between human beings via the instrumentality of computers" (Thurlow, Lengel, \& Tomic, 2004, p.83 cited in Norris, 2012). Higgins (1991) defined CMC as "human communication via computer". CMC is classified into two types: text-based CMC or audio/video-based CMC. According to Kawase (2009) CMC can be used both inside and outside of the classroom. By Using technology in education system "all students in a classroom can be connected via networked computers, and whole-class or small-group discussion can be held within such a class setting over a Local Area Network technology" (Kawase, 2009, p.2).

As Johnson (2006) stated "Synchronous applications of instructional technology can be traced to the use of closedcircuit television on university campuses in the 1940s". Learners' attitudes toward using of synchronous computermediated communication (SCMC) are positive, as according to studies of Warschauer (1996) "many learners consider SCMC activities interesting, comfortable, and creative".

"Some studies have demonstrated several advantages of using SCMC over face-to-face (FTF) oral exchanges. These studies show that during CMC chats, learners report reduced anxiety about participating, and increased motivation for using the target language, both of which result in greater quantities of target language production" (Kelm, 1992; Beauvois, 1995; Kern, 1995, Chun, 1998; cited in Cheon, 2003). These findings suggest that SCMC make language learners be active in learning environment where they have more opportunities for the target language's input and change their inter language capacities (Cheon, 2003). Similarly, Satar and Özdener (2008) investigated the effects of SCMC (both text-based \& voice chat) on speaking proficiency and anxiety. They found out that "speaking proficiency of both experimental groups increased, whereas there was a decrease in the anxiety levels only for the text chat groups". 
It is evident that non-English speakers need to improve their oral proficiency to be able in authentic communication. Dolati and Mikaili (2011) believed that Iranian language learners have no choice but to learn English to survive in an international relationship, global business and in an education environment. It is stated that "How Iranian students learn the spoken English proficiency is more complicated than in the case of other skills" (Dolati \& Mikaili, 2011, p.1142). Iranian learners have great improvement on writing, reading skills because of the amount of time spent on them in the classroom. Also the textbooks have focused greatly on developing reading comprehension and grammar. This is why teachers have limited time to spend on speaking drills. Teaching four skills may be main purpose of education system in Iran, however, it is found that within Iranian language educational system, the only skill that has received most priority is reading comprehension. Therefore, the problem of Iranian EFL learners as to how their oral proficiency in English can be improved still remains unsolved.

Considering the developments in technology and learners' incompetency in oral communication skills in the Iranian EFL context, the researchers aimed to study the impact of an instructional program based on SCMC, which is synchronous online communication, on learners' oral proficiency developments versus face-to-face (FTF) interaction. In fact, the present study attempted to address the following questions and research hypotheses:

RQ1\# Is there any differential effect between SCMC and FTF interaction on oral language proficiency of Iranian EFL learners?

RQ2\# Which of these instructional strategies (SCMC or FTF interaction) is more effective?

H1: There is a differential effect between SCMC and FTF interaction on the oral language proficiency of Iranian EFL learners.

H2: SCMC as an instructional strategy is more effective than FTF interaction on the oral language proficiency of Iranian EFL learners.

\section{Methodology}

\subsection{Participants}

The participants of this study consisted of EFL learners, namely 60 students (36 female, 24 male) enrolled in English intermediate-level English conversation classes at Shokouh-Iran institute. The convenience sampling procedure was used to select the participants that were equally assigned into the experimental group $(n=30)$ and the control group $(n=$ 30). In the experimental group, those who had access to Internet and were familiar to chat programs participated.

The proficiency level of all participants was measured through the Preliminary English Test (PET, 2007). Their homogeneity in terms of speaking performance was also assessed by a speaking pre-test. All of them were Iranian bilingual (Azari, Persian) learners. Their age ranged from 14 to 18 years and average age was 16.

\subsection{Instruments and Materials}

The researchers used the following instruments and materials to achieve the purpose of the study:

\subsubsection{The Speaking test}

The speaking test was selected from IELTS sample questions. This test was validated by a panel that consisted of EFL teachers in the Shoukoh-Iran Institute. The inter-rater reliability of the speaking test was also established. The Spearman rank-order coefficient $(R h o)$ formula showed a high degree of rater reliability $(\rho=.83)$. The oral questions included in the test are classified into three parts:

Part 1: Introduction and interview, this part of the test beings with the examiner introducing himself or herself and checking the candidate's identification. It then continues as an interview.

Part 2: Open-ended question, the candidates are asked to talk about something which is very important to him/her. In fact, personally relevant questions are asked.

Part 3: Two-way Discussion, this part of the test continues with the examiner's questions about some topics.

\subsubsection{Marking Scale for Speaking Skill}

This study applied the evaluation rubric, a conversation scale, designed by Hughes (2003) to assess and mark the results of the participants' performance in the pretest and posttest. It allows the tester in each interview both to assign candidates to a level holistically and to rate them on a six point scale for each of the following: Accuracy, Vocabulary, Fluency. These ratings are then weighted and totaled. This evaluation rubric was validated by several EFL teachers at Shoukoh-Iran Institute. It was identified as a suitable instrument for the current study.

\subsubsection{CQ Software}

In this quasi-experimental study, ICQ (I seek you), which is considered a widespread chat program in all over the world, has been preferred as the medium. As Compton (2002) found out that "ICQ presents the users with a split screen where they view their own messages in the top box as each letter is typed as well as each letter in their partners' messages in the bottom box as they are typed. Therefore, turn-taking is not restricted by the mode of communication and speakers can choose to co-construct the discourse, resulting in a closer resemblance to oral conversation".

\section{Procedure}

The procedures taken in this quasi-experimental study consisted of three phases: (1) pretesting, (2) treatment, and (3) post testing. At the pre testing phase, the sample was selected and the speaking pretest was administered to both groups.

As for the second phase of the study, the treatment lasted for four weeks with a total of twelve 90-minute sessions. The experimental group received the treatment based on the synchronous CMC (text-based). The chat sessions lasted 50-60 
minutes and took place at a determined time. Two-way conversations occurred, between the instructor (the first author of this paper) and one participant. Because of students' problems and time limitation, the instructor had to arrange different times for chat sessions in order not to interrupt their daily schedule. The control group received their lessons through a typically traditional FTF-based instruction.

Tasks designed by Pica, Kanagy, and Falodun (1993) were assigned in each session. They were (a) information gap, (b) problem solving, (c) jigsaw, and (d) decision making tasks. For the information gap task, the participants were required to exchange necessary information about pictures presented at their books. For the problem solving task, they were asked to find differences between pictures related to the ways to commemorate holidays. They were required to use the vocabularies taught before the task. The jigsaw task required the participants to sequence events described through pictures; they used adjective clauses with subject relative pronouns and object pronouns. For the decision making task, the participants exchanged information and made decisions about a seasonal holiday and a plan for its celebration. The topics for the tasks were selected from participants' own English textbook (Top Notch 3A). Lexical knowledge, accuracy, fluency and grammatical treatment were intended. During the third phase of the study, that is when the treatment procedure was over, subjects' proficiency skills were measured by a speaking posttest. The posttest was the same as the pretest. Their performance was scored through a valid speaking scale (Hughes. 2003).

\section{Data Analysis}

For the sake of clarity, this section is divided into two parts. The first part presents results of the descriptive data analysis and the second one provides results of the inferential data analysis.

\subsection{Descriptive Statistics: Participants' oral language proficiency scores}

As Table 1 shows, the performance of the experimental group $(M=68.43, S D=6.93)$ was very similar to that of the control group $(M=68.93, S D=6.77)$ on the oral proficiency test before the treatment. However, the experimental group $(M=87.83, S D=7.24)$ outperformed the control group $(M=77.03, S D=6.68)$ on the oral proficiency test after the treatment.

Before conducting inferential statistics for the results obtained above, the normality of the score distributions was checked. As Table 1 indicates, the values for the skewness and kurtosis fell within acceptable ranges that is between 1.0 and +1.0 .

Table 1. Descriptive Statistics for Pretest and Posttest Scores of the oral language proficiency test

\begin{tabular}{|c|c|c|c|c|}
\hline \multicolumn{3}{|l|}{ Variable } & \multirow{2}{*}{$\frac{\text { Statistic }}{68.43}$} & \multirow{2}{*}{$\begin{array}{c}\text { Std. Error } \\
1.266\end{array}$} \\
\hline Pretest & Experimental Group & Mean & & \\
\hline & & Std. Deviation & 6.937 & \\
\hline & & Skewness & .488 & .427 \\
\hline & & Kurtosis & -1.064 & .833 \\
\hline & Control Group & Mean & 68.93 & 1.236 \\
\hline & & Std. Deviation & 6.772 & \\
\hline & & Skewness & .354 & .427 \\
\hline & & Kurtosis & -1.162 & .833 \\
\hline \multirow[t]{8}{*}{ Posttest } & Experimental Group & Mean & 87.83 & 1.322 \\
\hline & & Std. Deviation & 7.240 & \\
\hline & & Skewness & -.595 & .427 \\
\hline & & Kurtosis & -.420 & .833 \\
\hline & Control Group & Mean & 77.03 & 1.220 \\
\hline & & Std. Deviation & 6.682 & \\
\hline & & Skewness & -.087 & .427 \\
\hline & & Kurtosis & -.238 & .833 \\
\hline
\end{tabular}

\subsection{Inferential Statistics: Participants' oral language proficiency scores}

This sub-section presents the outcomes of the independent-samples $t$-tests run to test the hypotheses formulated for participants' oral language proficiency performance in the current study. 
Table 2. Results of Independent-Samples Tests for pretest and posttest scores t-test for Equality of Means

\begin{tabular}{|c|c|c|c|c|c|c|c|}
\hline \multirow[b]{2}{*}{ Variable } & \multirow[b]{2}{*}{$\mathrm{t}$} & \multirow[b]{2}{*}{$\mathrm{df}$} & \multirow{2}{*}{$\begin{array}{l}\text { Sig. }(2- \\
\text { tailed) }\end{array}$} & \multirow{2}{*}{$\begin{array}{c}\text { Mean } \\
\text { Difference }\end{array}$} & \multirow{2}{*}{$\begin{array}{l}\text { Std. Error } \\
\text { Difference }\end{array}$} & $\begin{array}{c}95 \% \text { Confidence Interval of } \\
\text { the Difference }\end{array}$ & \multirow[b]{2}{*}{ Upper } \\
\hline & & & & & & Lower & \\
\hline Pretest & -.283 & 58 & .779 & -.500 & 1.770 & -4.043 & 3.043 \\
\hline Posttest & 6.004 & 58 & .000 & 10.800 & 1.799 & 7.199 & 14.401 \\
\hline
\end{tabular}

As shown in Table 2, at pretest (before the treatment) there was no statistically significant difference in the oral language proficiency scores between the experimental group $(M=68.43, S D=6.93)$ and the control group $(M=68.93$, $S D=6.77) ; t(58)=-.28, p=.77$. Even the magnitude of the differences in the means (mean difference $=-.50,95 \%$ CI: 4.04 to 3.04 ) was too small (eta squared $=.001$ ).

\section{Discussion}

The discussion of the findings is presented according to the questions of the study. The first question addressed the differential effect of SCMC and FTF interaction on Iranian EFL learners' speaking skill.

Through the first question, it was aimed to examine the differential effect of SCMC and FTF interaction on Iranian EFL learners' speaking skill. Results obtained show that the experimental group's performance in the pretest was similar to the control group's performance. However, the results at posttest demonstrated that there was a statistically significant difference between the posttest mean scores of the students in both groups, suggesting the differential effect of SCMC and FTF interaction.

This finding is in contrast with the social presence theory that considers the physical presence of the partner as a reason to better interpersonal relationships (Short, et al, 1976). It also states that FTF communication has a higher level of social presence than CMC. Accordingly, the conventional way is the most appropriate way for instruction. However, our findings are supportive of the findings that many researchers have recently reported on the efficacy of using technology as a communication medium in educational setting related to language pedagogy, which ultimately result in the richer message transference (Ehsan, 2008, Satar \& Özdener, 2008, YiXi, 2005). Therefore, SCMC can be considered as a richer medium of communication than synchronous CMC.

In general, the results obtained suggest that the first alternative hypothesis is accepted, that is $H 1$ : There is a differential effect of SCMC and FTF interaction on oral language proficiency of Iranian EFL learners.

Through the second question it was attempted to find out which of instructional strategies (SCMC or FTF interaction) is more effective. After the treatment, the results showed that the mean difference between the groups was $10.80,95 \%$ CI:7.19 to 14.40 , which means the magnitude of the difference was very large. It can be concluded that the experimental group's speaking ability was enhanced by the SCMC treatment.

This finding is supported by Lee (2002), Jurkowitz's (2008) research studies in which they found that SCMC encourages fluency and helps to enhance accuracy and rich lexical density. Satar and Özdener (2008) also found out that "learners had more rapid progress in speaking skill through SCMC and were able to use their new foreign language in real world situations with reasonable levels of proficiency". A few explanations for this finding seem appropriate. It can be argued that SCMC provides a non-threatening, positive and comfortable environment and thereby learners produce more language with high degree of accuracy and rich lexical density. The SCMC method is based on the belief that students can learn more effectively when the learning environment is comfortable for them; CMC environment is comfortable, cooperative, and non-threatening. The environment's condition is one of great differences between FTF interaction and SCMC.

In short, the results further support that the other alternative hypothesis is accepted as well, namely $H 2$ : SCMC as an instructional treatment is more effective than FTF interaction on oral language proficiency of Iranian EFL learners.

However, a word of caution is necessary here. Educators need to take into account that learners do not show the same reaction to CMC. Althaus (1997) concluded that "requiring participation in online components of a classroom poses difficulties, as not all students have the same level of technological expertise or motivation to engage with technology". He pointed out that some learners learn how to use technology easier and faster than other learners.

\subsection{Limitations}

As all studies, this study has some limitations. First of all, learners' access to computer and Internet networks has limited this study. The researchers had to delimitate the experimental groups' members to subjects who had E-friend or whose relatives live abroad. Therefore, they have chat experience. Secondly, because this study was conducted through Internet so disconnection problem limited it. Thirdly, subjects' school problem was out of the researchers' control. Sometimes they were absent due to school classes or exams.

\subsection{Suggestions for Future Studies}

The following are important issues to address for those who may be interested in this field:

1. A study needs to be undertaken with learners who have CMC competence so that the effect of SCMC can be investigated on speaking skill. This study suggests that students with greater ability for technology using can benefit greatly from the use of CMC technology. 
2. In this study, the number of males and females were approximately equal, but in future studies groups can be divided differently to see whether male and female learners achieve in the program equally or not.

3. This study can be replicated under the same conditions as was explained at the procedure section. Results of replication studies may provide further support for the efficacy of SCMC.

\section{Conclusion}

As it seems, SCMC (text-based) increased language production and enhanced the learners' attention on the linguistic forms. It can be an important tool to help learners gain self-confidence by involving them in a safe environment in which they can acquire target language. Previous studies have consistently discovered that CMC (text-base or oralbased) (a) promotes equal participation among language learners (Chun, 1994; Kern, 1995; Warschauer, 1996 cited in Abrams, 2003, p.170), (b) improves the chances for participation by learners who feel marginalized in FTF conversation (Warschauer, 1996 cited in Abrams, 2003, p.170), (c) increases students motivation (Beauvois, 1995; 1997 cited in Abrams, 2003, p.170).

In general, the results of the study suggest that SCMC can be an effective aid to improve speaking skill. The findings of this study indicate that the amount of language output after the treatment was greater for the experimental SCMC group. However, it would be unadvisable to conclude from these findings that FTF interaction is not a beneficial method for language teaching. As Kathleen (2004) states "make no mistake about it, FTF communication remains one of the primary roads to career success, even in this computer age".

In sum, despite the fact that a limited number of studies show that SCMC (text-based) enhance the development of speaking skill (Compton, 2002), this study concludes that due to a series of online tasks (jigsaw, information gap, decision making, problem solving) through SCMC (text-based), those EFL learners' speaking performance participating in this study improved in terms of lexical, fluency and accuracy.

\section{References}

Abrams, Zs. (2003). The effect of Synchronous and Asynchronous CMC on Oral Performance on German. The Modern Language Journal, 87 (2), 157-167.

Althaus, S. (1997). Computer-mediated communication in the university classroom: An experiment with online discussions. Communication Education, 46 (3), 158-174.

Beauvois, M. H. (1995). E-talk: Attitudes and motivation in computer-assisted classroom discussion. Computers and the Humanities, 28, 177-190.

Beauvois, M. H. (1997). Write to speak: the effect of electronic communication on the oral achievement of fourth semester French students. In J.Muyskens (Ed.), new ways of learning and teaching: Issues in language program direction (pp. 93-116).

Cheon, H. (2003). The viability of computer mediated communication in the Korean secondary EFL classroom. Asian EFL Journal. Vol.5 Issue 1 Article 2. Retriever December 1 1, 2012 from http://www.asion-efljournal.com/march03.sub2.phd.

Chun, D.M. (1994). Using computer networking to facilitate the acquisition of interactive competence. System, 22 (1), 17-31.

Chun, D. M. (1998). Using Computer Assisted Class Discussion to Facilitate the Acquisition Interactive Competence. In J. Swaffar, S. Romano, P. Markley \& K. Arens (eds,). Language Learning Online: Theory and Practice 2. Austin, Tx: Labyrinth Publications. 57-80.

Compton, L. (2002). From chatting to oral fluency: using chat to improve self-confidence and increase willingness to communicate. Retrieved January $5^{\text {th }}, 2013$ from http://www.tewjournal.org/ICQ\%2HC.

Dolati, I. \& Mikaili, P. (2011). Opinion related to the main reasons on Iranian students' difficulties in spoken English proficiency. Australian Journal of basic and Applied Science. 01/2011. . Retrieved March 23 ${ }^{\text {rd }}, 2012$, from http://www.ajbasweb.com

Ehsan, N., Mirza, E., \& Ahmad, M. (2008). Impact of computer-mediated communication on virtual teams' performance: An empirical study. World Academy of Science, Engineering and Technology. 42: 694-703

Higgins, R. (1991). Computer-mediated cooperative learning: Synchronous and asynchronous communication between students learning nursing diagnosis. Unpublished doctoral dissertation. University of Toronto. Retrieved February $15^{\text {th }}, 2012$, from http://www.cybercorp.net/rhiggins/thesis.

Hughes, A. (2003). Testing for language teachers, Cambridge university press. (pp. 131-133).

Johnson, G. M. (2006). Synchronous and asynchronous text-based CMC in educational contexts: A review of recent research. TechTrends, Vol.50. No.4 pp. 46-53.

Jurkowitz, L. A. (2008). Interaction, meaning-making, and accuracy in synchronous CMC discussion: the experiences of a university-level intermediated French class. Retrieved May $4^{\text {th }} 2012$ from http://arizona.openrepository.com/arizona.

Kathleen, A. (2004). Face to face communication, making human connections in a technologh-driven world. CALCO Journal, Vol.2 No.2 pp.12-18. 
Kawase, A. (2009). Second language acquisition and synchronous computer mediated communication. Retrieved February $14^{\text {th }}, 2012$, from http://www.tc.columbia.edu/tesolalwebjoournal.

Kelm, O.R. (1992). The use of synchronous computer networks in second language instruction: A preliminary report. Foreign Language Annals, 25, 441-445.

Kern, R.G. (1995). Restructuring classroom interaction with networked computers: Effects on quantity and characteristics of language production. Modern Language Journal, 79, 457-476.

Lee, C.K.M. (2002). Literacy practices in computer-mediated communication in Hong Kong. The reading matrix, Vol. 2, No.2. pp. 1-25. . Retrieved September 11 ${ }^{\text {th }}$, 2012, from https://www.mediensprache.net/archiv/2925.pdf

Murad, T. M. (2009). The effect of task-based language teaching on developing speaking skills among the Palestinian secondary EFL students in Israel and their attitudes towards English. The Asian EFL Journal. Retrieved March $24^{\text {th }}, 2012$, from http://asian0efl-journal.com/category/thesis.

Norris, A. R. (2012). Computer-mediated communication and globalization: considering social academic, and business factors. Student Pulse, an online academic students Journal. Vol,4 No.2. Retrieved September $18^{\text {th }}$, 2012, from http://www.studentpulse.com.

Pica, T., Kanagy, R., \& Falodun, J. (1993). Choosing and using communication tasks for second language research and instruction. In G. Crookes \& S. M. Gass (Eds.), Tasks and language learning: Integrating theory and practice (pp. 9-34). Clevedon, England: Multilingual Matters.

Satar, H. M, \& Özdener, N. (2008). Computer-mediated communication in foreign language education: use of target language and learner perception. Turkish Online Journal of Distance Education. Vol. 9 No. 2 Article 9. Retrieved January $15^{\text {th }}, 2013$ from http://www.toj/de.

Short, J.A., Williams, E., \& Christie, B. (1976). The social psychology of telecommunication. London: John Wiley \& Sons.

Thurow, C., Lengel, L.B., \& Tomic, A. (2004). Computer-Mediated communication: social interaction and the Internet. (pp.77-85). Thousand Oaks, CA: Sage Publications.

Warschauer, M. (1996). Comparing FTF and electronic communication in the second language classroom. CALICO Journal, 13 (2), 7-26.

$\mathrm{Xu}$, Yi. (2005). Synchronous Computer-mediated Communication and Second Language Acquisition --Current Researches and Future Directions. 